\title{
The mediated effect of HIV risk perception in the relationship between peer education and HIV testing uptake among three key populations in China
}

\author{
Yuxi Lin, Chuanxi Li, Lin Wang, Kedi Jiao and Wei Ma*
}

\begin{abstract}
Background: Peer education and HIV risk perception are related to HIV testing uptake among key populations. We aimed to examine the association between peer education, HIV risk perception, and HIV testing uptake, as well as to evaluate the mediated effect of HIV risk perception in the relationship between peer education and HIV testing uptake.

Methods: We conducted a cross-sectional survey among 1188 HIV-uninfected or unknown participants from populations of men who have sex with men (MSM), female sex workers (FSWs), and drug users (DUs) in seven cities of China. Partial correlation analysis and regression analysis were employed to examine the associations among peer education, HIV risk perception, and HIV testing uptake. Mediation analysis was conducted to assess whether HIV risk perception mediated the hypothesized association.

Results: Receiving peer education was associated with higher odds of HIV testing uptake among MSM, FSWs and DUs. Perceiving risk of HIV infection was associated with higher odds of HIV testing uptake among MSM and DUs. Among MSM, the relationship between peer education and HIV testing uptake was mediated by moderate risk perception of HIV (indirect effect: $0.53,95 \% \mathrm{Cl} 0.07$ to 1.21), and by high risk perception of HIV (indirect effect: 0.50, 95\% Cl 0.01 to 1.17). Among DUs, the relationship between peer education and HIV testing uptake was mediated by moderate risk perception of HIV (indirect effect: 1.80, 95\% Cl 0.57 to 3.45 ).

Conclusions: Participants who received peer education tended to perceive their risk of HIV infection, which in turn was associated with increased HIV testing uptake among MSM and DUs. Therefore, in addition to peer education interventions, more report about HIV epidemic and risk assessment should also be scaled up to enhance HIV risk perception among key populations.
\end{abstract}

Keywords: HIV testing, Peer education, HIV risk perception, Mediated effect, Key populations

*Correspondence: weima@sdu.edu.cn

Department of Epidemiology, School of Public Health, Cheeloo College of Medicine, Shandong University, 44 West Wenhua Road, Jinan,

Shandong 250012, People's Republic of China

\section{Background}

In China, sexual transmission is the current primary route of HIV transmission [1]. Among the new diagnosed HIV/AIDS cases in 2019, sexual transmission accounted for $96.7 \%$ (male-male sexual transmitted cases accounted for $23.0 \%$, and heterosexual transmitted cases accounted for $73.7 \%$ ) [2]. Men who have sex with men (MSM),

(c) The Author(s) 2021. This article is licensed under a Creative Commons Attribution 4.0 International License, which permits use, sharing, adaptation, distribution and reproduction in any medium or format, as long as you give appropriate credit to the original author(s) and the source, provide a link to the Creative Commons licence, and indicate if changes were made. The images or other third party material in this article are included in the article's Creative Commons licence, unless indicated otherwise in a credit line to the material. If material is not included in the article's Creative Commons licence and your intended use is not permitted by statutory regulation or exceeds the permitted use, you will need to obtain permission directly from the copyright holder. To view a copy of this licence, visit http://creativeco mmons.org/licenses/by/4.0/. The Creative Commons Public Domain Dedication waiver (http://creativecommons.org/publicdomain/ zero/1.0/) applies to the data made available in this article, unless otherwise stated in a credit line to the data. 
female sex workers (FSWs), and drug users (DUs) are key populations for HIV infection in China due to their unsafe sexual behaviors, such as unprotected sex and multiple sexual partners [3-5].

HIV testing is an essential step for effective HIV prevention [6], offering the possibility to receive treatment, change sexual behavior and improve health and quality of life [7]. The first goal of the 90-90-90 cascade target proposed by the Joint United Nations Programme on HIV/ AIDS (UNAIDS) is that $90 \%$ of people living with HIV know their HIV status by 2020 [8]. At present, this goal have only been achieved within limited regions $[9,10]$, and HIV testing services are still underutilized among key populations around the world, given that multiple factors such as poor HIV-related knowledge, stigma, and discrimination hinder their access to HIV services [1113]. Globally, about half of key populations living with HIV are not aware of their HIV status [14]. In China, the annual HIV testing rate among MSM is low, ranging from 44.6 to $69 \%$ [15], followed by DUs with an annual HIV testing proportion of $25.8 \%$ [16] and FSWs of $24.4 \%$ [5]. It is therefore imperative to promote HIV testing uptake among key populations to control HIV epidemic.

Peer education intervention is a widely used strategy targeting key populations to promote HIV prevention and treatment, involving recruiting members of a specific group at-risk for HIV to encourage peers to improve HIV knowledge and reduce risky sexual behaviors [1719]. A previous meta-analysis proved that peer education can effectively promote HIV testing uptake among key populations [18], and another systematic review also demonstrated that the information about the location, availability and the importance of HIV testing services for key populations provided by peer education are related to HIV testing uptake [20]. A peer-based intervention program conducted among MSM in China has proved that peer education can be used to improve HIV testing and linkage to care [21]. Additionally, an intervention model in Vietnam has been proved effective to improve HIV risk perception among community and factory youth [19].

To date, only about half of key populations perceived their risk of HIV infection globally [22, 23]. The relationship between risk perception and HIV testing uptake among key populations have been evaluated in a variety of studies, however, the results are conflicting. For example, a cross-section study conducted among MSM in China indicated that those who perceived higher risk of HIV tended to test for HIV [22], and a study conducted among DUs indicated that perceptions of no risk or lowrisk for HIV infection was barrier to HIV testing services [24]. Besides, some studies conducted in sub-Saharan Africa, Germany and India also demonstrated that risk perception for HIV is one of facilitators of HIV testing uptake among MSM, FSWs and DUs, because they might want to know their results when perceived their risk of HIV infection [20, 25, 26]. On the contrary, a study conducted in Peru showed that those participants who perceived high risk for HIV were less likely to test frequently [27].

There is a dearth of studies exploring the mediated effect of HIV risk perception in the relationship between peer education and HIV testing uptake. Previous studies assessed the relationship among peer education, risk perception of HIV and HIV testing uptake separately. In this study, we examined these relationships among three key populations in China. Furthermore, we explored whether risk perception of HIV mediated the relationship between peer education and HIV testing uptake. We hypothesized that (1) peer education is positively associated with HIV testing uptake among MSM, FSWs, and DUs and (2) the association is mediated through the risk perception of HIV infection.

\section{Methods \\ Participants}

A cross-sectional survey was conducted among three groups at-risk for HIV in seven cities of China in 2018, with MSM recruited from Shijiazhuang and Xiamen, FSWs recruited from Zhengzhou, Nanchang and Biyang, and DUs recruited from Qingdao and Shanghai. Considering the capacity for recruiting adequate key populations and the feasibility of the survey, we selected two provinces from the north and south of China for each key population. Considering the speed of recruitment, we chose the capital of targeting provinces as study sites for different populations, and added Biyang as one of study sites for FSWs.

Convenience sampling was used to recruit participants with the help of local community based organizations (CBOs). Prior to beginning this survey, all people accessing to $\mathrm{CBOs}$ were confirmed their eligibility and those eligible person were invited to participate in this survey by staff of local CBOs. Those provided informed consent and voluntarily participated in this study were included in this survey. The inclusion criteria included: (1) 18 years or older; (2) had high-risk sexual behaviors (had sex with men for MSM, exchanged sex for money or other goods for FSWs, and took drugs for DUs) in the past 12 months; (3) self-reported HIV infection status was negative or unknown; and (4) provided informed consent and voluntarily participated in this study.

\section{Procedures}

Those who were willing to participate in study would be directed in a quiet and private room in local CBOs. 
The purpose, content and procedures of this study were explained to the eligible participants by a trained team member and signed informed consent was obtained. Every participant was assigned a code to obtain questionnaires. Staff then oriented participants to input their codes through smartphones to get the electronic questionnaires. Paper questionnaires were also prepared for those who did not use smartphones. Participants who completed the questionnaires were reimbursed $50 \mathrm{RMB}$ (7.55 USD).

\section{Measures}

\section{Social-demographics}

Participants were asked about their gender, age, time of residence, education level, monthly income and marital status. MSM also reported their sexual orientation and DUs reported the type of drugs they used and the route of drug use.

\section{Sexual behaviors}

We measured participants' high-risk sexual behaviors by asking about whether or not they used condom consistently and experienced condom breakage or slippage in anal sex in the past month. We dichotomized these variable after removing those who did not had anal sex in the past month.

MSM participants answered 4 questions about their condom use frequency during sex with their male fixed sexual partners, non-commercial male casual sexual partners, commercial male sexual partners and female sexual partners in the past month. FSWs participants answered 2 questions about their condom use frequency during sex with their clients in the past month and with their husband/boyfriend in the past month. DUs participants answered 4 questions about their condom use frequency during sex with partners after using drugs, in multiple-partner sexual behaviors, in sex with spouse, and with commercial sexual partners in the past month. In the analysis, we dichotomized this variable ("Never", "Sometimes", or "Every time") into "had condomless sex" and "did not have condomless sex". Participants who reported "Never" or "Sometimes" were categorized as had condomless sex in the past month.

MSM participants were asked if they had experienced condom breakage or slippage in anal sex with male sexual partners in the past month. FSWs participants were asked if they had experienced condom breakage or slippage in sex with their clients in the past month. DUs participants were asked if they had experienced condom breakage or slippage during sexual intercourse with partners after using drugs in the past month. Participants who answered "Yes" were categorized as "experienced condom breakage of slippage in sex in the past month".

\section{Peer education}

Participants was asked if they had participated peer education concerning HIV prevention in the past year ("Yes" or "No"). Those responded "Yes" were categorized as "having received peer education". Peer education was defined as activity in which peer educators from key populations deliver the knowledge about HIV prevention or information about HIV related services through multiple methods, including face-to-face conversation, posters, leaflets, lectures or internet.

\section{Risk perception of HIV infection}

Participants were asked if they felt that the HIV infection among MSM/FSWs/DUs is serious ("Serious", "Moderate", "Low", or "Don't know"). Those responded "Serious" were categorized as "perceived high risk of HIV infection", those responded "Moderate" were categorized as "perceived moderate risk of HIV infection", and those responded "Low" or "Don't know" were categorized as "did not perceive risk of HIV infection".

\section{History of HIV testing}

Participants were asked about their HIV testing history ("Never tested", "Tested before 12 months", "Tested one time in the past 12 months", or "Tested two times or more in the past 12 months"). In analyses, we dichotomized this variable into had versus did not have testing for HIV in the past 12 months. Those who responded "Tested one time in the past 12 months" or "Tested two times or more in the past 12 months" were categorized had HIV testing in the past 12 months.

\section{Statistical analysis}

The database was developed by one team member, with the data of electric questionnaires exported from "Wenjuanxing", a professional platform for online questionnaires distribution, filling and collection, and the data of paper questionnaires inputted by EpiData 3.1. A total of 1220 questionnaires was received, and 32 questionnaires were excluded due to responses with missing data, leaving a finial sample size of 1188 participants. Descriptive analysis and partial correlation analysis were conducted in SPSS 24.0 and mediation analysis was conducted in the software R4.0.2. All statistic tests were two-sided, and $p<0.05$ was considered as statistically significant. We conducted chi-square tests to assess the difference of the distribution of each variable among groups of participants categorized by their history of HIV testing in the past 12 months.

To assess the conditional effects of variables on HIV testing uptake, we fitted 3 separate multivariable logistic regression models. The first model assessed 
socio-demographic correlates of HIV testing uptake, variables with a $p$-value higher than 0.3 were excluded in subsequent models [28]. Then the second model was fitted to assess the conditional effects of high-risk sexual behavioral associated with HIV testing uptake after removing those who did not have sex in the past month. The third model was fitted to assess peer education and risk perception of HIV associated with HIV testing uptake.

Then, we examine the partial correlations between peer education, risk perception of HIV and HIV testing uptake among MSM, FSWs, and DUs.

Meditation analyses were conducted among every different populations. First, we conducted multinomial logistic regression for different levels of HIV risk perception on peer education; doing so provided us with the " $a$ " path (Fig. 1) parameter estimates and standard errors. Then, we fitted a logistic regression model for HIV testing uptake on peer education and HIV risk perception, and used the parameter estimates and standard errors of moderate and high HIV risk perception as our " $b$ " path (Fig. 1). Finally, we used the "medci" function of "RMediation" package in the software R4.0.2 to estimate each mediated effect and its asymmetric confidence interval $(\mathrm{CI})$ to determine whether mediated effects were significant [29]. The alpha was 0.05, and type was "prodclin". A significant mediation effect existed when CI did not contain zero.

\section{Results}

Descriptive statistics are presented in Table 1. We received a total of 1227 questionnaires, 39 incomplete questionnaires were excluded. A total of 1188 participants were included in this study, including 419 MSM, 400 FSWs and 369 DUs. About one third (127/419, $30.3 \%)$ MSM, one quarter (93/400, 23.3\%) FSWs and $44.4 \%(164 / 369)$ DUs reported that they had not been tested for HIV in the past 12 months. Participants who had HIV testing in the past 12 months had a higher

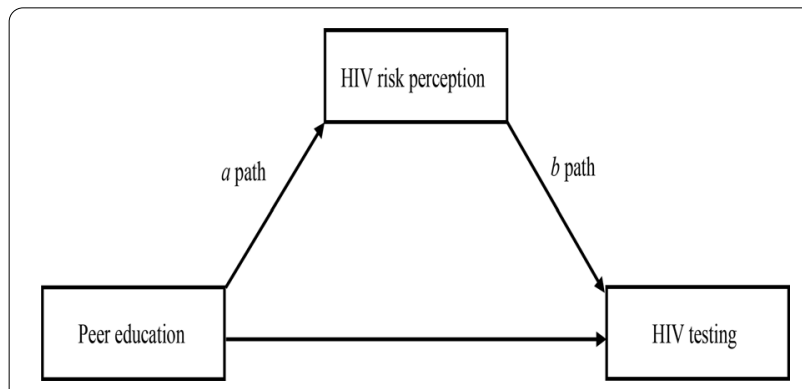

Fig. 1 The $a$ path and $b$ path in mediation analysis proportion of receiving peer education and perceiving moderate or high HIV risk among three populations $(p<0.05)$ (Table 1).

Tables 2, 3 and 4 present factors independently associated with HIV testing uptake among MSM, FSWs and DUs, respectively. Table 2 shows that sexual orientation, education level, peer education and HIV risk perception were related to HIV testing uptake in the past 12 months among MSM $(p<0.05)$. Table 3 shows that age, duration of local residence, education level and peer education were related to HIV testing among FSWs $(p<0.05)$. Table 4 shows that gender, age, education level, monthly income, marital status, peer education and HIV risk perception were related to HIV testing uptake among DUs $(p<0.01)$.

Partial correlations among peer education, risk perception of HIV and HIV testing uptake in the past 12 months among MSM, FSWs and DUs are shown in Table 5 . Among MSM and DUs, peer education, risk perception of HIV and HIV testing uptake were interrelated with each other among every population $(p<0.001)$. Among FSWs, peer education was related to HIV risk perception and HIV testing uptake $(p<0.001)$, however, the correlation of HIV risk perception and HIV testing uptake was not statistically significant $(p>0.05)$.

Table 6 presents $a$ paths, $b$ paths, estimates and 95\% CIs for mediated effects among MSM, FSWs and DUs. Among MSM, the mediated effects of moderate and high HIV risk perception (indirect effect: $0.53,95 \%$ CI 0.07 , 1.21; and indirect effect: $0.50,95 \%$ CI $0.01,1.17$ ) in the relationship between peer education and HIV testing were significant when compared to perceived of no HIV risk. Besides, among DUs, compared to not perceived the risk of HIV, only moderate risk perception of HIV mediated (indirect effect: $1.80,95 \%$ CI $0.57,3.45$ ) the relationship of peer education to HIV testing. However, the mediated effects of moderate and high risk perception of HIV were not statistically significant (indirect effect: $-0.52,95 \%$ CI $-1.44,0.33$; and indirect effect: $0.76,95 \%$ $\mathrm{CI}-0.61,2.52)$ in the relationship of peer education on HIV testing uptake among FSWs.

\section{Discussion}

In this survey conducted among MSM, FSWs and DUs in 7 cities in China, we found that receiving peer education was positively associated with HIV risk perception and HIV testing uptake among three key populations, and that HIV risk perception was positively associated with HIV testing uptake among MSM and DUs. We also found that HIV risk perception mediated the relationship between peer education and HIV testing uptake among MSM and DUs. This study extends previous research on relationship between peer education, HIV risk perception 
Table 1 Socio-demographic, sexual behavioral, peer education, and HIV risk perception characteristics comparing participants who had HIV testing to those who had not in the past 12 months among three key populations in China $(\mathrm{N}=1188)$

\begin{tabular}{|c|c|c|c|c|c|c|c|c|c|}
\hline \multirow[t]{3}{*}{ Variables } & \multicolumn{9}{|c|}{ HIV testing in the past 12 months } \\
\hline & \multicolumn{3}{|c|}{ MSM $(N=419)$} & \multicolumn{3}{|c|}{ FSWs $(N=400)$} & \multicolumn{3}{|c|}{ DUs $(N=369)$} \\
\hline & $\begin{array}{l}\text { No } \\
\text { n (\%) }\end{array}$ & $\begin{array}{l}\text { Yes } \\
\text { n (\%) }\end{array}$ & $p$ & $\begin{array}{l}\text { No } \\
\text { n (\%) }\end{array}$ & $\begin{array}{l}\text { Yes } \\
\text { n (\%) }\end{array}$ & $p$ & $\begin{array}{l}\text { No } \\
\mathrm{n}(\%)\end{array}$ & $\begin{array}{l}\text { Yes } \\
\text { n (\%) }\end{array}$ & $p$ \\
\hline \multicolumn{10}{|l|}{ Gender } \\
\hline Male & $127(100.0)$ & $292(100.0)$ & - & - & - & & $75(45.7)$ & $148(72.2)$ & $<0.001$ \\
\hline Female & - & - & & $93(100.0)$ & $307(100.0)$ & & $89(54.3)$ & $57(27.8)$ & \\
\hline \multicolumn{10}{|l|}{ Age } \\
\hline $18-25$ & $72(56.7)$ & $154(52.7)$ & 0.690 & $18(19.4)$ & $19(6.2)$ & $<0.001$ & $20(12.2)$ & $84(41.0)$ & $<0.001$ \\
\hline $26-35$ & $29(22.8)$ & $79(27.1)$ & & $36(38.7)$ & $87(28.3)$ & & $37(22.6)$ & $57(27.8)$ & \\
\hline $36-45$ & $14(11.0)$ & $37(12.7)$ & & $15(16.1)$ & $146(47.6)$ & & $54(32.9)$ & $29(14.1)$ & \\
\hline 46 or older & $12(9.4)$ & $22(7.5)$ & & $24(25.8)$ & $55(17.9)$ & & $53(32.3)$ & $35(17.1)$ & \\
\hline \multicolumn{10}{|l|}{ Duration of local residence } \\
\hline 2 years or less & $43(33.9)$ & $81(27.7)$ & 0.207 & $49(52.7)$ & $218(71.0)$ & 0.001 & $16(9.8)$ & $32(15.6)$ & 0.097 \\
\hline More than 2 years & $84(66.1)$ & $211(72.3)$ & & $44(47.3)$ & $89(29.0)$ & & $148(90.2)$ & $173(84.4)$ & \\
\hline \multicolumn{10}{|l|}{ Education level } \\
\hline Middle school or lower & $23(18.1)$ & $33(11.3)$ & 0.016 & $57(61.3)$ & $250(81.4)$ & $<0.001$ & $36(22.0)$ & $50(24.4)$ & $<0.001$ \\
\hline High school & $33(26.0)$ & $54(18.5)$ & & $19(20.4)$ & $46(15.0)$ & & $86(52.4)$ & $44(21.5)$ & \\
\hline College or higher & $71(55.9)$ & $205(70.2)$ & & $17(18.3)$ & $11(3.6)$ & & $42(25.6)$ & $111(54.1)$ & \\
\hline \multicolumn{10}{|l|}{ Monthly income (RMB) ${ }^{\mathrm{a}}$} \\
\hline 3000 or less & $57(44.9)$ & $115(39.4)$ & 0.483 & $50(53.8)$ & $227(73.9)$ & 0.001 & $93(56.7)$ & $96(46.8)$ & 0.021 \\
\hline $3001-5000$ & $37(29.1)$ & $86(29.5)$ & & $26(28.0)$ & $50(16.3)$ & & $38(23.2)$ & $75(36.6)$ & \\
\hline 5001 or higher & $33(26.0)$ & $91(31.2)$ & & $17(18.3)$ & $30(9.8)$ & & $33(20.1)$ & $34(16.6)$ & \\
\hline \multicolumn{10}{|l|}{ Marital status } \\
\hline Single & $95(74.8)$ & $227(77.7)$ & $0.626^{b}$ & $30(32.3)$ & $51(16.6)$ & 0.004 & $75(45.7)$ & $161(78.5)$ & $<0.001$ \\
\hline Married/co-habitation & $28(22.0)$ & $53(18.2)$ & & $53(57.0)$ & $208(67.8)$ & & $72(43.9)$ & $38(18.5)$ & \\
\hline Divorced/widowed/segregated & $4(3.1)$ & $12(4.1)$ & & $10(10.8)$ & $48(15.6)$ & & $17(10.4)$ & $6(2.9)$ & \\
\hline \multicolumn{10}{|l|}{ Sexual orientation } \\
\hline Gay & $57(44.9)$ & $203(69.5)$ & $<0.001$ & & & & & & \\
\hline Other & $70(55.1)$ & $89(30.5)$ & & & & & & & \\
\hline \multicolumn{10}{|l|}{ Types of drugs used } \\
\hline Single & & & & & & & 119 (72.6) & $146(71.2)$ & 0.776 \\
\hline Multiple & & & & & & & $45(27.4)$ & $59(28.8)$ & \\
\hline \multicolumn{10}{|l|}{ Injected drug in the past month } \\
\hline No & & & & & & & $160(97.6)$ & $193(94.1)$ & 0.110 \\
\hline Yes & & & & & & & $4(2.4)$ & $12(5.9)$ & \\
\hline \multicolumn{10}{|l|}{ Condomless sex (past month) } \\
\hline No & $90(72.4)$ & $211(72.3)$ & 0.970 & $42(45.2)$ & $149(48.5)$ & 0.568 & $106(64.6)$ & $89(43.4)$ & $<0.001$ \\
\hline Yes & $35(27.6)$ & $81(27.7)$ & & $51(54.8)$ & $158(51.5)$ & & $58(35.4)$ & $116(56.6)$ & \\
\hline \multicolumn{10}{|c|}{ Condom breakage or slippage (past month) } \\
\hline No & $115(90.6)$ & $265(90.8)$ & 0.948 & $38(40.9)$ & $123(40.1)$ & 0.891 & 109 (66.5) & $133(64.9)$ & 0.750 \\
\hline Yes & $12(9.4)$ & $27(9.2)$ & & $55(59.1)$ & $184(59.9)$ & & $55(33.5)$ & $72(35.1)$ & \\
\hline \multicolumn{10}{|l|}{ Peer education } \\
\hline No & $86(67.7)$ & $135(46.2)$ & $<0.001$ & $62(66.7)$ & $96(31.3)$ & $<0.001$ & $55(33.5)$ & $25(12.2)$ & $<0.001$ \\
\hline Yes & $41(32.3)$ & $157(53.8)$ & & $31(33.3)$ & $211(68.7)$ & & 109 (66.5) & 180 (87.8) & \\
\hline \multicolumn{10}{|l|}{ HIV risk perception } \\
\hline No & $65(51.2)$ & $88(30.1)$ & $<0.001$ & $67(72.0)$ & $189(61.6)$ & 0.005 & $125(76.2)$ & $69(33.7)$ & $<0.001$ \\
\hline Moderate & $31(24.4)$ & $92(31.5)$ & & $18(19.4)$ & $44(14.3)$ & & $24(14.6)$ & $88(42.9)$ & \\
\hline High & $31(24.4)$ & 112 (38.4) & & 8 (8.6) & 74 (24.1) & & $15(9.1)$ & $48(23.4)$ & \\
\hline
\end{tabular}


Table 1 (continued)

Bolded $p$ values are statistically significant at $p<0.05$

a 1 USD = 6.62 RMB in 2018

b Fisher's exact test

Table 2 Factors associated with HIV testing in the past 12 months among MSM in China

\begin{tabular}{|c|c|c|c|c|c|c|}
\hline \multirow[t]{2}{*}{ Variables } & \multicolumn{2}{|l|}{ Model $1(N=419)$} & \multicolumn{2}{|l|}{ Model $2^{\mathrm{a}}(\mathrm{N}=260)$} & \multicolumn{2}{|l|}{ Model $3(N=419)$} \\
\hline & AOR $(95 \% \mathrm{Cl})$ & $p$ value & AOR $(95 \% \mathrm{Cl})$ & $p$ value & AOR $(95 \% \mathrm{Cl})$ & $p$ value \\
\hline \multicolumn{7}{|l|}{ Age } \\
\hline $18-25$ & Ref & - & & & & \\
\hline $26-35$ & $1.32(0.72,2.42)$ & 0.373 & & & & \\
\hline $36-45$ & $1.34(0.56,3.21)$ & 0.509 & & & & \\
\hline 46 or older & $1.30(0.45,3.76)$ & 0.631 & & & & \\
\hline \multicolumn{7}{|l|}{ Duration of local residence } \\
\hline 2 years and less & Ref & - & & & & \\
\hline More than 2 years & $1.15(0.70,1.89)$ & 0.583 & & & & \\
\hline \multicolumn{7}{|l|}{ Education } \\
\hline Middle school or lower & Ref & - & Ref & - & Ref & - \\
\hline High school & $1.01(0.49,2.08)$ & 0.974 & $1.29(0.50,3.32)$ & 0.605 & $1.25(0.59,2.63)$ & 0.566 \\
\hline College or higher & $1.87(0.97,3.58)$ & 0.061 & $1.63(0.73,3.66)$ & 0.232 & $2.24(1.17,4.29)$ & 0.015 \\
\hline \multicolumn{7}{|l|}{ Monthly income $(\mathrm{RMB})^{\mathrm{b}}$} \\
\hline 3000 or less & Ref & - & & & & \\
\hline $3001-5000$ & $1.20(0.68,2.10)$ & 0.534 & & & & \\
\hline 5001 or higher & $1.25(0.68,2.28)$ & 0.476 & & & & \\
\hline \multicolumn{7}{|l|}{ Marital status } \\
\hline Single & Ref & - & & & & \\
\hline Married/co-habitation & $0.91(0.43,1.20)$ & 0.800 & & & & \\
\hline Divorced/widowed/segregated & $1.00(0.28,3.58)$ & 0.999 & & & & \\
\hline \multicolumn{7}{|l|}{ Sex orientation } \\
\hline Gay & Ref & - & Ref & - & Ref & - \\
\hline Other & $0.36(0.23,0.56)$ & $<0.001$ & $0.49(0.28,0.88)$ & 0.018 & $0.38(0.24,0.60)$ & $<0.001$ \\
\hline \multicolumn{7}{|l|}{ Condomless sex (past month) } \\
\hline No & & & Ref & - & & \\
\hline Yes & & & $0.65(0.36,1.18)$ & 0.155 & & \\
\hline \multicolumn{7}{|c|}{ Condom breakage or slippage (past month) } \\
\hline No & & & Ref & - & & \\
\hline Yes & & & $0.72(0.30,1.73)$ & 0.466 & & \\
\hline \multicolumn{7}{|l|}{ Peer education } \\
\hline No & & & & & Ref & - \\
\hline Yes & & & & & $2.20(1.38,3.50)$ & 0.001 \\
\hline \multicolumn{7}{|l|}{ HIV risk perception } \\
\hline No & & & & & Ref & - \\
\hline Moderate & & & & & $2.00(1.15,3.47)$ & 0.014 \\
\hline High & & & & & $2.79(1.62,4.81)$ & $<0.001$ \\
\hline
\end{tabular}

Bolded $p$ values are statistically significant at $p<0.05$

a Excluded those had not anal sex in the past month

b 1 USD $=6.62 \mathrm{RMB}$ in 2018 
Table 3 Factors associated with HIV testing in the past 12 months among FSWs in China

\begin{tabular}{|c|c|c|c|c|c|c|}
\hline \multirow[t]{2}{*}{ Variables } & \multicolumn{2}{|l|}{ Model $1(N=400)$} & \multicolumn{2}{|l|}{ Model $2^{\mathrm{a}}(\mathrm{N}=398)$} & \multicolumn{2}{|l|}{ Model $3(N=400)$} \\
\hline & AOR (95\%Cl) & $p$ value & AOR $(95 \% \mathrm{Cl})$ & $p$ value & AOR $(95 \% \mathrm{Cl})$ & $p$ value \\
\hline \multicolumn{7}{|l|}{ Age } \\
\hline $18-25$ & Ref & - & Ref & - & Ref & - \\
\hline $26-35$ & $1.55(0.62,3.87)$ & 0.346 & $1.39(0.55,3.53)$ & 0.483 & $1.33(0.50,3.54)$ & 0.570 \\
\hline $36-45$ & $4.51(1.65,12.31)$ & 0.003 & $3.88(1.39,10.82)$ & 0.010 & $2.95(1.00,8.67)$ & 0.049 \\
\hline 46 or older & $0.95(0.34,2.68)$ & 0.922 & $0.80(0.28,2.30)$ & 0.672 & $0.66(0.21,2.02)$ & 0.461 \\
\hline \multicolumn{7}{|l|}{ Duration of local residence } \\
\hline 2 years and less & Ref & - & Ref & - & Ref & - \\
\hline More than 2 years & $0.56(0.32,0.95)$ & 0.032 & $0.56(0.33,0.96)$ & 0.034 & $0.75(0.42,1.32)$ & 0.320 \\
\hline \multicolumn{7}{|l|}{ Education } \\
\hline Middle school or lower & Ref & - & Ref & - & Ref & - \\
\hline High school & $0.63(0.32,1.25)$ & 0.183 & $0.63(0.31,1.25)$ & 0.184 & $0.51(0.25,1.06)$ & 0.071 \\
\hline College or higher & $0.24(0.10,0.58)$ & 0.001 & $0.22(0.09,0.55)$ & 0.001 & $0.19(0.07,0.49)$ & 0.001 \\
\hline \multicolumn{7}{|l|}{ Monthly income $(\mathrm{RMB})^{\mathrm{b}}$} \\
\hline 3,000 or less & Ref & - & Ref & - & Ref & - \\
\hline $3001-5000$ & $0.63(0.34,1.18)$ & 0.152 & $0.61(0.32,1.15)$ & 0.126 & $0.66(0.34,1.29)$ & 0.224 \\
\hline 5001 or higher & $0.73(0.33,1.58)$ & 0.416 & $0.71(0.33,1.56)$ & 0.397 & $0.86(0.39,1.91)$ & 0.707 \\
\hline \multicolumn{7}{|l|}{ Marital status } \\
\hline Single & Ref & - & Ref & - & Ref & - \\
\hline Married/co-habitation & $1.87(0.92,3.80)$ & 0.086 & $1.96(0.94,4.10)$ & 0.074 & $1.81(0.82,4.00)$ & 0.141 \\
\hline Divorced/widowed/Segregated & $2.13(0.80,5.65)$ & 0.130 & $2.25(0.84,6.05)$ & 0.109 & $1.95(0.68,5.62)$ & 0.217 \\
\hline \multicolumn{7}{|l|}{ Condomless sex (past month) } \\
\hline No & & & Ref & - & & \\
\hline Yes & & & $0.76(0.44,1.33)$ & 0.336 & & \\
\hline \multicolumn{7}{|c|}{ Condom breakage or slippage (past month) } \\
\hline No & & & Ref & - & & \\
\hline Yes & & & $0.90(0.52,1.55)$ & 0.701 & & \\
\hline \multicolumn{7}{|l|}{ Peer education } \\
\hline No & & & & & Ref & - \\
\hline Yes & & & & & $3.51(1.94,6.33)$ & $<0.001$ \\
\hline \multicolumn{7}{|l|}{ HIV risk perception } \\
\hline No & & & & & Ref & - \\
\hline Moderate & & & & & $0.63(0.29,1.35)$ & 0.234 \\
\hline High & & & & & $1.80(0.74,4.38)$ & 0.198 \\
\hline
\end{tabular}

Bolded $p$ values are statistically significant at $p<0.05$

a Excluded those had not anal sex in the past month

b 1 USD $=6.62$ RMB in 2018

and HIV testing uptake separately by exploring the mediated effect of HIV risk perception in the relationship between peer education and HIV testing uptake.

The results showed that peer education was positively associated with HIV testing uptake among MSM, FSWS and DUs. This finding confirmed and added to previous meta-analysis that demonstrated peer education had a positive impact on promoting HIV testing uptake among MSM, IDUs and FSWs [18]. Firstly, peer education could advance the awareness of the importance of HIV testing and provide the information about the location and availability of HIV services, which increase accessing to HIV testing services [20]. Second, peers could offering social support and referrals for services, which improve HIV testing uptake [30]. Besides, the emotional support provided by peers could help key populations overcome specific barriers to accessing HIV testing services [31]. Additionally, compared to traditional interventions, peer education intervention is more trustable and confidential for key populations, thus can better reach 
Table 4 Factors associated with HIV testing in the past 12 months among DUs in China

\begin{tabular}{|c|c|c|c|c|c|c|}
\hline \multirow[t]{2}{*}{ Variables } & \multicolumn{2}{|l|}{ Model $1(N=369)$} & \multicolumn{2}{|l|}{ Model $2^{\mathrm{a}}(\mathrm{N}=210)$} & \multicolumn{2}{|l|}{ Model $3(N=369)$} \\
\hline & AOR (95\%Cl) & $p$ value & AOR $(95 \% \mathrm{Cl})$ & $p$ value & AOR $(95 \% \mathrm{Cl})$ & $p$ value \\
\hline \multicolumn{7}{|l|}{ Gender } \\
\hline Male & Ref & - & Ref & - & Ref & - \\
\hline Female & $0.28(0.16,0.49)$ & $<0.001$ & $0.18(0.08,0.45)$ & $<0.001$ & $0.36(0.18,0.69)$ & 0.002 \\
\hline \multicolumn{7}{|l|}{ Age } \\
\hline $18-25$ & Ref & - & Ref & - & Ref & - \\
\hline $26-35$ & $0.52(0.23,1.17)$ & 0.112 & $0.71(0.24,2.10)$ & 0.539 & $0.18(0.06,0.52)$ & 0.002 \\
\hline $36-45$ & $0.24(0.10,0.60)$ & 0.002 & $0.41(0.09,1.85)$ & 0.243 & $0.09(0.03,0.29)$ & $<0.001$ \\
\hline 46 or older & $0.18(0.07,0.46)$ & $<0.001$ & $0.19(0.04,0.99)$ & 0.048 & $0.05(0.02,0.17)$ & $<0.001$ \\
\hline \multicolumn{7}{|l|}{ Duration of local residence } \\
\hline 2 years and less & Ref & - & & & & \\
\hline More than 2 years & $1.22(0.54,2.79)$ & 0.635 & & & & \\
\hline \multicolumn{7}{|l|}{ Education } \\
\hline Middle school or lower & Ref & - & Ref & - & Ref & - \\
\hline High school & $0.11(0.05,0.25)$ & $<0.001$ & $0.40(0.10,1.66)$ & 0.206 & $0.12(0.05,0.28)$ & $<0.001$ \\
\hline College or higher & $0.31(0.13,0.75)$ & 0.009 & $0.72(0.16,3.27)$ & 0.668 & $0.62(0.23,1.70)$ & 0.358 \\
\hline \multicolumn{7}{|l|}{ Monthly income (RMB) $)^{b}$} \\
\hline 3,000 or less & Ref & - & Ref & - & Ref & - \\
\hline $3001-5000$ & $5.06(2.41,10.62)$ & $<0.001$ & $8.36(2.57,27.18)$ & $<0.001$ & $4.72(2.07,10.78)$ & $<0.001$ \\
\hline 5,001 or higher & $1.63(0.75,3.51)$ & 0.216 & $4.08(1.22,13.58)$ & 0.022 & $1.32(0.57,3.08)$ & 0.518 \\
\hline \multicolumn{7}{|l|}{ Marital status } \\
\hline Single & Ref & - & Ref & - & Ref & - \\
\hline Married/Co-habitation & $0.14(0.07,0.28)$ & $<0.001$ & $0.11(0.03,0.33)$ & $<0.001$ & $0.24(0.11,0.52)$ & $<0.001$ \\
\hline Divorced/Widowed/Segregated & $0.18(0.05,0.58)$ & 0.004 & $0.11(0.02,0.61)$ & 0.011 & $0.22(0.06,0.85)$ & 0.028 \\
\hline \multicolumn{7}{|l|}{ Types of drugs used } \\
\hline Single & Ref & - & & & & \\
\hline Multiple & $1.08(0.60,1.96)$ & 0.790 & & & & \\
\hline \multicolumn{7}{|l|}{ Injected drug in the past month } \\
\hline No & Ref & - & & & & \\
\hline Yes & $0.84(0.22,3.27)$ & 0.800 & & & & \\
\hline \multicolumn{7}{|l|}{ Condomless sex (past month) } \\
\hline No & & & Ref & - & & \\
\hline Yes & & & $1.09(0.43,2.75)$ & 0.856 & & \\
\hline \multicolumn{7}{|c|}{ Condom breakage or slippage (past month) } \\
\hline No & & & Ref & - & & \\
\hline Yes & & & $0.52(0.24,1.12)$ & 0.094 & & \\
\hline \multicolumn{7}{|l|}{ Peer education } \\
\hline No & & & & & Ref & - \\
\hline Yes & & & & & $16.93(6.12,46.82)$ & $<0.001$ \\
\hline \multicolumn{7}{|l|}{ HIV risk perception } \\
\hline No & & & & & Ref & - \\
\hline Moderate & & & & & $4.23(2.03,8.83)$ & $<0.001$ \\
\hline High & & & & & $4.21(1.81,9.77)$ & 0.001 \\
\hline
\end{tabular}

Bolded $p$ values are statistically significant at $p<0.05$

a Excluded those had not anal sex in the past month

b 1 USD $=6.62 \mathrm{RMB}$ in 2018 
Table 5 Partial correlations between peer education, HIV risk perception infection and HIV testing among MSM, FSWs, and DUs in China

\begin{tabular}{|c|c|c|c|c|c|c|c|}
\hline \multirow[t]{2}{*}{ Variable } & \multirow[t]{2}{*}{ Group } & \multicolumn{2}{|c|}{ HIV risk perception } & \multicolumn{2}{|c|}{ HIV testing } & \multicolumn{2}{|c|}{$\begin{array}{l}\text { HIV risk perception } \rightarrow \mathrm{HIV} \\
\text { testing }\end{array}$} \\
\hline & & $r$ & $p$ value & r & $p$ value & $r$ & $p$ value \\
\hline \multirow[t]{3}{*}{ Peer education } & $\mathrm{MSM}^{\mathrm{a}}$ & 0.10 & 0.044 & 0.19 & $<0.001$ & 0.20 & $<0.001$ \\
\hline & $\mathrm{FSWs}^{\mathrm{b}}$ & 0.27 & $<0.001$ & 0.28 & $<0.001$ & 0.09 & 0.073 \\
\hline & DUs $s^{c}$ & 0.15 & 0.004 & 0.32 & $<0.001$ & 0.34 & $<0.001$ \\
\hline
\end{tabular}

Table 6 Mediation analysis of HIV risk perception in the relationship between peer education and HIV testing among overall three key populations, among MSM, FSWs, and DUs in China

\begin{tabular}{|c|c|c|c|c|c|}
\hline \multirow[t]{2}{*}{ Group } & \multirow{2}{*}{$\begin{array}{l}\text { Level of risk perception } \\
\text { of HIV }\end{array}$} & \multirow{2}{*}{$\begin{array}{l}\text { a path (peer education } \rightarrow \text { HIV risk } \\
\text { perception) } \\
\text { Est (se) }\end{array}$} & \multirow{2}{*}{$\begin{array}{l}b \text { path (HIV risk } \\
\text { perception } \rightarrow \text { HIV testing) } \\
\text { Est (se) }\end{array}$} & \multicolumn{2}{|c|}{ Mediated effect } \\
\hline & & & & Est (se) & $95 \% \mathrm{Cl}$ \\
\hline \multirow[t]{2}{*}{$M M^{a}$} & Moderate & $0.76(0.25)^{* *}$ & $0.69(0.28)^{*}$ & $0.53(0.30)$ & {$[0.07,1.21]$} \\
\hline & High & $0.48(0.24)^{*}$ & $1.03(0.28)^{* *}$ & $0.50(0.30)$ & {$[0.01,1.17]$} \\
\hline \multirow[t]{2}{*}{$\mathrm{FSWs}^{\mathrm{b}}$} & Moderate & $1.13(0.35)^{* *}$ & $-0.50(0.38)$ & $-0.52(0.44)$ & {$[-1.44,0.33]$} \\
\hline & High & $1.60(0.37)^{* *}$ & $0.45(0.45)$ & $0.76(0.80)$ & {$[-0.61,2.52]$} \\
\hline \multirow[t]{2}{*}{ DUs $s^{c}$} & Moderate & $1.24(0.34)^{* *}$ & $1.44(0.38)^{* *}$ & $1.80(0.74)$ & {$[0.57,3.45]$} \\
\hline & High & $0.87(0.49)$ & $1.44(0.43)^{* *}$ & $1.28(0.87)$ & {$[-0.11,3.27]$} \\
\hline
\end{tabular}

\footnotetext{
a The results adjusted for education level and sexual orientation

b The results adjusted for age, duration of local residence and education level

c The results adjusted for gender, age, education level, monthly income and married status

${ }^{*} p<0.05 ;{ }^{* *} p<0.01$

Bolded $\mathrm{Cl}$ does not contain zero
}

"hidden" populations who may have limited access to traditional outreach [21, 32]. Moreover, the cost-effect of peer education is also less than normal outreach [33, 34]. Therefore, peer education about HIV testing should be strengthened and scaled up to improve HIV testing uptake among key populations.

In this study, compared to perception of no HIV risk, perception of moderate and high HIV risk not only directly affected HIV testing uptake, but also mediated the effects of peer education on HIV testing uptake among MSM. Among group of DUs, moderate perception of HIV risk mediated the relationship between peer education and HIV testing uptake. Those participants who have received peer education about HIV prevention tended to perceive their risk of HIV infection, and in turn were more likely to be tested for HIV. This finding is consistent with the health belief model, which shows that knowledge is the premise of risk perception and when people perceiving a risk for a health threat, including perceived susceptibility and perceived severity of the threat, they will be more likely to participate in changing health related behaviors [35]. There is a dearth of studies exploring the mediated effect of HIV risk perception in the association between peer education and HIV testing, but the relationship of HIV risk perception to peer education and to HIV testing have been widely documented. Our finding is in line with the previous study, indicating that peer education had positive association with HIV risk perception [19] and with study showed that HIV risk perception has positive association with HIV testing uptake among MSM [25]. Therefore, in addition to peer education, strategies improving HIV risk perception are necessary to advance HIV testing uptake among key populations. The report about the HIV epidemic and education on HIV-related knowledge among key populations should be scaled up to improve awareness of HIV risk. Besides, prevention providers should strengthen their efforts in risk assessment and recommend people with high risk of HIV infection for testing. 
We found that peer education had an effect on moderate risk perception of HIV, but the effect on high perception of HIV risk was not statistically significant among DUs when compared to no perception of HIV risk. It is likely that some DUs underestimated their risk of HIV infection. A study showed that the use of drugs increased the risk of HIV transmission by encouraging high-risk sexual behaviors, such as condomless sex and multiple sexual partners, which were related to increasing HIV infection risk [36]. In our study, most of the participants did not inject drug in the past month, so they might perceive that they had no or low risk of HIV infection because they did not sharing needles and ignored their risk of HIV infection through sexual transmission. Previous study showed that not sharing needles might be a reason of underestimated their risk of HIV infection among DUs [37]. More education on HIV transmission and risk factors of HIV infection are needed to help DUs to accurately assess their risk for acquiring HIV.

It is notably that there is a possible mediated effect of HIV risk perception among FSWs, however, this effect is not statistically significant. Further large-scale studies are needed to confirm this finding. We found that peer education was associated with risk perception of HIV, while perception of HIV infection was not associated with HIV testing when adjusting peer education. These findings suggest that FSWs as an illegal position in China suffered multiple barriers to access to HIV testing services though they had perceived their HIV risk. Factors hindering accessing to HIV testing services frequently investigated among FSWs are, poor HIV-related knowledge, stigma, and discrimination [12, 38-40]. In order to increase HIV testing uptake, in addition to peer education and HIV risk perception interventions, further research should explore effective interventions to help FSWs overcoming these difficulties to accessing HIV testing services.

There are limitations to this study. Firstly, limited by the nature of cross-sectional study, the temporal relationship between variables were not clear, and therefore causal relationships could not be warranted. Specifically, the main variables were measured in different time scales, peer education and history of HIV testing was measured within the past 12 months, while the risk perception was measured when the survey was conducted. Secondly, study participants were recruited at $\mathrm{CBOs}$, and therefore may not have been representative of key populations who were not accessing these sites. Thirdly, we used only a single-item to measure HIV risk perception. Further study are suggested to use a comprehensive measure to evaluate HIV risk perception. Finally, because our participants were key populations, their responses were subject to social desirability, thus some response might be inaccurate, especially those related to sexual behaviors and HIV. However, most interviews were administered online, which would enhance the reliability of data to some extent.

\section{Conclusion}

In summary, our study demonstrated that the risk perception of HIV was an important mediator of peer education and HIV testing uptake among key populations, especially among MSM and DUs. Therefore, in addition to peer education interventions, more report about HIV epidemic and risk assessment should also be strengthen to enhance HIV risk perception among key populations.

\section{Abbreviations}

HIV: Human immunodeficiency virus; AIDS: Acquired immune deficiency syndrome; CBOs: Community-based organizations; MSM: Men who have sex with men; FSWs: Female sex workers; DUs: Drug users; UNAIDS: The Joint United Nations Programme on HIV/AIDS.

\section{Acknowledgements}

Acknowledgements should be made to all study participants, and staff members at local CBOs in studying sites.

\section{Authors' contributions}

WM conceived the study. YL, CL, LW, KJ participated in data collection. YL and $\mathrm{KJ}$ participated in data analysis. The manuscript was prepared by $Y L$ and was carefully revised and edited by WM and CL. All authors read and approved the final manuscript.

\section{Funding}

This work was supported by the National Key Research and Development Program of China under Grant (2017YFE0103800) and the National Science and Technology Major Project under Grant (2018ZX10721102-003-004).

\section{Availability of data and materials}

The datasets analyzed during the current study are not publicly available but are available from the corresponding author on reasonable request.

\section{Declarations}

Ethics approval and consent to participate

Our study was approved by the Ethical Review Committee (ERC) of School of Public Health in Shandong University. All participants will provide consent prior to taking part in the study.

\section{Consent for publication}

Not applicable.

\section{Competing interests}

The authors declare that they have no competing interests.

Received: 29 October 2020 Accepted: 15 March 2021

Published online: 25 March 2021

References

1. Wu Z, Chen J, Scott SR, McGoogan JM. History of the HIV epidemic in China. Curr HIV/AIDS Rep. 2019;16(6):458-66.

2. Bureau of disease control and prevention, National Health Commision. The new progress in China's AIDS prevention and control in 2019. Chin J AIDS STD. 2019;25(12):1205.

3. Sun X, Xiao Y, Peng Z, Wang N. Frequent implementation of interventions may increase HIV infections among MSM in China. Sci Rep. 2018;8(1):451. 
4. Chow EP, Muessig KE, Yuan L, Wang Y, Zhang X, Zhao R, et al. Risk behaviours among female sex workers in China: a systematic review and data synthesis. PLoS ONE. 2015;10(3):e0120595.

5. Jiang Z, Xiu C, Yang J, Zhang X, Liu M, Chen X, et al. HIV test uptake and related factors amongst heterosexual drug users in Shandong province, China. PLoS ONE. 2018;13(10):e0204489.

6. Buchbinder SP, Liu AY. CROI 2016: hot spots in HIV infection and advances in HIV prevention. Top Antivir Med. 2016;24(1):10-28.

7. Platteau T, van Lankveld J, Apers L, Fransen K, Rockstroh J, Florence E. HIV testing for key populations in Europe: a decade of technological innovation and patient empowerment complement the role of health care professionals. HIV Med. 2018;19(Suppl 1):71-6.

8. UNAIDS. 90-90-90 An ambitious treatment target to help end the AIDS epidemic: UNAIDS; 2017. https://www.unaids.org/sites/default/files/ media_asset/90-90-90_en.pdf. Accessed 26 July 2020.

9. Essex M, Makhema J, Lockman S. Reaching 90-90-90 in Botswana. Curr Opin HIV AIDS. 2019;14(6):442-8.

10. The LH. Cities getting to $90-90-90$ and beyond. Lancet HIV. 2019;6(10):e639.

11. Beyrer C, Sullivan PS, Sanchez J, Dowdy D, Altman D, Trapence G, et al. A call to action for comprehensive HIV services for men who have sex with men. Lancet. 2012;380(9839):424-38.

12. Tokar A, Broerse JEW, Blanchard J, Roura M. HIV testing and counseling among female sex workers: a systematic literature review. AIDS Behav. 2018;22(8):2435-57.

13. Lan CW, Lin C, Thanh DC, Li L. Drug-related stigma and access to care among people who inject drugs in Vietnam. Drug Alcohol Rev. 2018;37(3):333-9.

14. UNAIDS. UNAIDS global AIDS update 2020 report: UNAIDS; 2020. https:// aids2020.unaids.org/report/. Accessed 26 July 2020.

15. Jiang $H_{\text {, Hong } H}$, Dong $H$, Jiang J, He L. HIV testing and risks of sexual behavior among HIV-negative men who have sex with men in Ningbo, China. Int J Environ Res Public Health. 2020;17(4):1322.

16. Han L, Zhou C, Li Z, Poon AN, Rou K, Fuller S, et al. Differences in risk behaviours and HIV/STI prevalence between low-fee and mediumfee female sex workers in three provinces in China. Sex Transm Infect. 2016;92(4):309-15.

17. Cabral HJ, Davis-Plourde K, Sarango M, Fox J, Palmisano J, Rajabiun S. Peer support and the HIV continuum of care: results from a multi-site randomized clinical trial in three urban clinics in the United States. AIDS Behav. 2018;22(8):2627-39.

18. He J, Wang Y, Du Z, Liao J, He N, Hao Y. Peer education for HIV prevention among high-risk groups: a systematic review and meta-analysis. BMC Infect Dis. 2020;20(1):338.

19. Ngo AD, Ha TH, Rule J, Dang CV. Peer-based education and the integration of HIV and sexual and reproductive health services for young people in Vietnam: evidence from a project evaluation. PLoS ONE. 2013;8(11):e80951.

20. Nnko S, Kuringe E, Nyato D, Drake M, Casalini C, Shao A, et al. Determinants of access to HIV testing and counselling services among female sex workers in sub-Saharan Africa: a systematic review. BMC Public Health. 2019;19(1):15

21. Yan $H$, Zhang $R$, Wei $C$, Li J, Xu J, Yang H, et al. A peer-led, communitybased rapid HIV testing intervention among untested men who have sex with men in China: an operational model for expansion of HIV testing and linkage to care. Sex Transm Infect. 2014;90(5):388-93.

22. Fan $W$, Yin L, Qian HZ, Li D, Shao Y, Vermund SH, et al. HIV risk perception among HIV negative or status-unknown men who have sex with men in China. Biomed Res Int. 2014;2014:232451.

23. Khajehkazemi R, Haghdoost A, Navadeh S, Setayesh H, Sajadi L, Osooli $M$, et al. Risk and vulnerability of key populations to HIV infection in Iran; knowledge, attitude and practises of female sex workers, prison inmates and people who inject drugs. Sex Health. 2014;11(6):568-74.

24. Du J, Lombardi C, Evans E, Jiang H, Zhao M, Meng YY. A mixed methods approach to identifying factors related to voluntary HIV testing among injection drug users in Shanghai China. Int J Infect Dis 2012;16(7):e498-503.

25. Marcus U, Gassowski M, Drewes J. HIV risk perception and testing behaviours among men having sex with men (MSM) reporting potential transmission risks in the previous 12 months from a large online sample of MSM living in Germany. BMC Public Health. 2016;16(1):1111.

26. Woodford MR, Chakrapani V, Newman PA, Shunmugam M. Barriers and facilitators to voluntary HIV testing uptake among communities at high risk of HIV exposure in Chennai. India Glob Public Health. 2016;11(3):363-79.

27. Vargas SK, Konda KA, Leon SR, Brown B, Klausner JD, Lindan C, et al. The relationship between risk perception and frequency of HIV testing among men who have sex with men and transgender women, Lima Peru. AIDS Behav. 2018;22(Suppl 1):26-34.

28. Wei C, Cheung DH, Yan H, Li J, Shi LE, Raymond HF. The impact of homophobia and HIV stigma on HIV testing uptake among Chinese men who have sex with men: a mediation analysis. J Acquir Immune Defic Syndr. 2016;71(1):87-93.

29. Tofighi D, Mackinnon DP. RMediation: an R package for mediation analysis confidence intervals. Behav Res Methods. 2011:43(3):692-700.

30. Dutcher MV, Phicil SN, Goldenkranz SB, Rajabiun S, Franks J, Loscher BS, et al. "Positive Examples": a bottom-up approach to identifying best practices in HIV care and treatment based on the experiences of peer educators. AIDS Patient Care STDS. 2011;25(7):403-11.

31. Okeke NL, Ostermann J, Thielman NM. Enhancing linkage and retention in HIV care: a review of interventions for highly resourced and resourcepoor settings. Curr HIV AIDS Rep. 2014;11(4):376-92.

32. Simoni JM, Nelson KM, Franks JC, Yard SS, Lehavot K. Are peer interventions for HIV efficacious? A systematic review. AIDS Behav. 2011;15(8):1589-95

33. Bagnall AM, South J, Hulme C, Woodall J, Vinall-Collier K, Raine G, et al. A systematic review of the effectiveness and cost-effectiveness of peer education and peer support in prisons. BMC Public Health. 2015;15:290.

34. Chola L, Fadnes LT, Engebretsen IM, Nkonki L, Nankabirwa V, Sommerfelt $\mathrm{H}$, et al. Cost-effectiveness of peer counselling for the promotion of exclusive breastfeeding in Uganda. PLoS ONE. 2015;10(11):e0142718.

35. Carmel S. The health belief model in the research of AIDS-related preventive behavior. Public Health Rev. 1990;18(1):73-85.

36. Hoenigl M, Chaillon A, Moore DJ, Morris SR, Smith DM, Little SJ. Clear links between starting methamphetamine and increasing sexual risk behavior: a cohort study among men who have sex with men. J Acquir Immune Defic Syndr. 2016;71(5):551-7.

37. Nguyen TMT, Tran BX, Fleming M, Pham MD, Nguyen LT, Nguyen ALT, et al. HIV knowledge and risk behaviors among drug users in three Vietnamese mountainous provinces. Subst Abus Treat Prev Policy. 2019:14(1):3.

38. Kim HY, Grosso A, Ky-Zerbo O, Lougue M, Stahlman S, Samadoulougou C, et al. Stigma as a barrier to health care utilization among female sex workers and men who have sex with men in Burkina Faso. Ann Epidemiol. 2018;28(1):13-9.

39. Chanda MM, Perez-Brumer AG, Ortblad KF, Mwale M, Chongo S, Kamungoma N, et al. Barriers and facilitators to HIV testing among Zambian female sex workers in three transit hubs. AIDS Patient Care STDS. 2017;31(7):290-6.

40. Asadi-Aliabadi M, Abolghasemi J, Rimaz S, Majdzadeh R, Rostami-Maskopaee F, Merghati-Khoei E. Barriers to health service utilization among Iranian female sex workers: a qualitative study. J Prev Med Public Health. 2018;51(2):64-70.

\section{Publisher's Note}

Springer Nature remains neutral with regard to jurisdictional claims in published maps and institutional affiliations. 